\title{
Implicit attitudes toward the elderly among health professionals and undergraduate students in the health field: a systematic review
}

\author{
Atitude implícita em relação ao idoso em profissionais de saúde e estudantes \\ de cursos de graduação da área da saúde: uma revisão sistemática
}

Madson Alan Maximiano-Barreto, ${ }^{1}$ (D) Bruna Moretti Luchesi, ${ }^{2}$ Marcos Hortes Nisihara Chagas $^{1}$

\begin{abstract}
Objective: To perform a systematic review of articles evaluating implicit attitudes of health professionals and undergraduate students in the health field toward the elderly.

Methods: The PsyciNFO, PubMed, Web of Science, Scopus and LILACS databases were searched for relevant articles published in English, Portuguese and Spanish using the following search terms: implicit attitude AND (elderly OR aged OR older people). Seven articles were selected.

Results: The majority of studies were conducted in developed countries and found negative attitudes toward the elderly, with males exhibiting more negative attitudes than females.

Conclusion: The articles analyzed in this review demonstrate an implicitly negative attitude among professionals and students in the field of health toward the elderly.

Keyword: Implicit attitude; health professional; health student; elderly.
\end{abstract}

\section{Resumo}

Objetivo: Realizar uma revisão sistemática de artigos publicados que avaliam atitudes implícitas em relação ao idoso de profissionais de saúde e estudantes de cursos de graduação da área da saúde.

Método: A pesquisa foi realizada nos bancos de dados PsycINFO, PubMed, Web of Science, Scopus e LILACS, buscando artigos relevantes publicados em inglês, português e espanhol. Foram utilizados os seguintes operadores booleanos: implicit attitude AND (elderly OR aged OR older people). Foram selecionados 7 artigos.

Resultado: A maioria dos estudos selecionados foi realizada em países desenvolvidos e relatou uma atitude negativa em relação aos idosos. Indivíduos do sexo masculino apresentaram mais atitude negativa que os do sexo feminino.

Conclusão: Os artigos analisados nesta revisão mostram que a atitude negativa em relação ao público idoso está implicitamente presente entre os profissionais e estudantes da área da saúde. Descritores: Atitude implícita; profissional da saúde; estudante da saúde; idoso.

\footnotetext{
${ }^{1}$ Departamento de Gerontologia, Universidade Federal de São Carlos, São Carlos, SP, Brazil. 2 Universidade Federal de Mato Grosso do Sul (UFMS), Três Lagoas, MS, Brazil.

Submitted Dec 07 2018, accepted for publication Feb 162019.

Suggested citation: Maximiano-Barreto MA, Luchesi BM, Chagas MHN. Implicit attitudes toward the elderly among health professionals and undergraduate students in the health field: a systematic review. Trends Psychiatry Psychother. 2019;41(4):415-421. http://dx.doi.org/10.1590/2237-6089-2018-0108
} 


\section{Introduction}

The world is undergoing rapid demographic transition, with an increase in life expectancy, accompanied by a considerable increase in the prevalence of noncommunicable diseases, ${ }^{1}$ such as depression, diabetes mellitus, systemic arterial hypertension and chronic degenerative diseases (e.g., Alzheimer's and Parkinson's disease). These and other diseases underscore the need for qualified health professionals to meet the needs of the growing elderly population. ${ }^{2-5}$

Conversely, studies have revealed that health professionals and students in the health field prefer not to work with the elderly. ${ }^{6,7}$ A study involving 113 nursing students found that only $2.7 \%$ reported having interest in working with this target public, whereas $68.1 \%$ reported having no interest and the rest demonstrated neither interest nor disinterest. ${ }^{6}$ In another study involving 100 neurologists, $77 \%$ had positive attitudes toward the elderly, $20 \%$ had negative attitudes and the remaining $3 \%$ had neutral attitudes. However, it should be pointed out that the $77 \%$ with positive attitudes had more contact with disciplines in the field of geriatrics. ${ }^{8}$

This disinterest of health professionals and students may be the result of the lack of disciplines focusing on geriatrics and gerontology in undergraduate courses, which contrasts with policies for elderly care..$^{9,10}$ Difficulties in dealing with situations of abandonment, death and dependence, communication problems during appointments and the larger number of treatments that these patients undergo in comparison to young adults are also factors that likely exert an influence on such attitudes. ${ }^{11-13}$ The lack of interest on the part of health professionals has direct implications on the health of the elderly and could increase the risk of death among these individuals. ${ }^{14,15}$

An individual's evolution in society leads to the development of diverse behaviors and attitudes. Attitudes have two characteristics (explicit and implicit). ${ }^{16}$ An implicit attitude is a prejudice presented in an irrational, unconscious or uncontrollable way. ${ }^{17}$ It is a thought or attitude that arises in a particular situation. ${ }^{17}$ According to Greenwald et al., ${ }^{18}$ implicit attitudes are "introspectively unidentified (or inaccurately identified) traces of past experience that mediate favorable or unfavorable feelings toward an attitude object" (p. 11). In other words, such attitudes are responses given to particular situations based on an individual's beliefs. Implicit attitudes generally occur automatically and/or spontaneously, with no assistance from the conscious mind.

There are a number of tests for measuring implicit attitudes. For such, it is necessary to have a particular object and/or situation with which to analyze an individual's position. ${ }^{19}$ In the 19 th century, F. C. Donders suggested tests or techniques for measuring implicit attitudes based on the analysis of the time interval between a stimulus and the response of the individual being analyzed. ${ }^{20}$ The test continues to be the most widely used one to assess implicit attitudes.

The aim of the present study was to perform a review of published articles that evaluate implicit attitudes toward elderly patients on the part of health professionals and undergraduate students in the health field.

\section{Method}

A systematic review was conducted through searches on the Psycinfo, PubMed, Web of Science, Scopus and LILACS databases for relevant articles using the following search terms and Boolean operators: implicit attitude AND (elderly OR aged OR older people).

Inclusion criteria were articles describing empirical studies published in English, Spanish or Portuguese that directly addressed implicit attitudes toward the elderly among health professionals and/or undergraduate students in the health field. No restriction was imposed regarding the year of publication. Articles that evaluated implicit attitudes regarding race, gender or other issues, editorials, letters to the editor, literature reviews, dissertations and validation studies were excluded from the review.

The searches in the aforementioned databases were performed independently by two reviewers. The Mendeley program was used for the identification of duplicate references. Titles and abstracts were then analyzed based on the eligibility criteria. For such, each article was characterized using a Microsoft Excel ${ }^{\circledR}$ 2013 spreadsheet created by the authors on August 28, 2018. Articles that met the inclusion criteria were submitted to full-text analysis. Hand searches were also performed on the reference lists of the selected papers for the identification of other relevant publications. The selection process is detailed in Figure 1. The Preferred Reporting Items for Systematic Reviews and MetaAnalyses (PRISMA) statement was followed in the present review. ${ }^{21}$

\section{Results}

A total of 1,356 articles were retrieved from the databases searched. After the screening process, seven were selected for the systematic review (Table 1 ). 


\section{Characteristics of the studies selected}

A total of 670 individuals were analyzed in the seven studies included in this review. ${ }^{22-28}$ Sample sizes in the individual studies ranged from $26^{23}$ to $300^{25}$ participants. A total of 438 participants were female. $22-28$ The study conducted by Merz et al. ${ }^{28}$ presented the lowest mean age among participants ( mean $=18.0$ years; $S D=$
0.46 ), and the study by Nash et al. ${ }^{26}$ showed the highest mean age $($ mean $=35.1$ years; SD $=7.4$ ).

Five of the studies were conducted at universities only. ${ }^{22-25,28}$ Nash et al. ${ }^{26}$ performed their studies at both a university and a hospital, and Ruiz et al. ${ }^{27}$ developed an on-line study. The studies were conducted on four continents (North America, South America, Europe

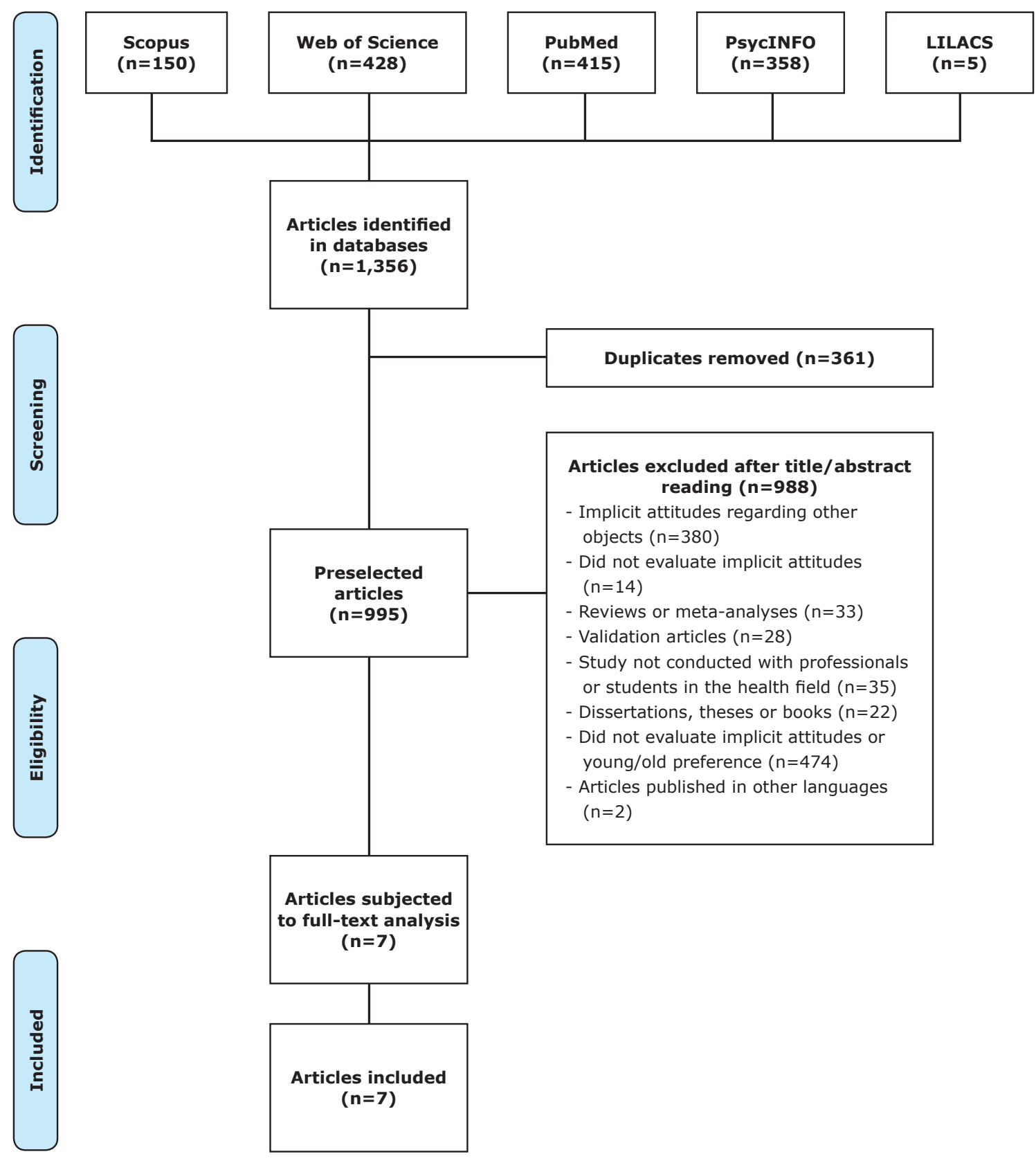

Figure 1 - Flowchart following recommendations of the Preferred Reporting Items for Systematic Reviews and Meta-Analyses (PRISMA) statement ${ }^{21}$ 
and Australia)22-28; four were conducted in the United States. $22,23,27,28$

Regarding study design, three were crosssectional, ${ }^{24,26,27}$ three experimental ${ }^{22,23,25}$ and one was a case-control study. ${ }^{28}$

The studies involved professionals and students from the following fields: nursing, ${ }^{26}$ gerontology, ${ }^{28}$ medicine ${ }^{27}$ and psychology. ${ }^{22,23,25}$ Five of the studies restricted participation to students, $22-25,28$ and two included both health professionals and students. ${ }^{26,27}$

\section{Assessment of implicit attitudes}

The Implicit Association Test (IAT) was developed by Greenwald et al. ${ }^{30}$ with the aim of assessing implicit attitudes regarding particular issues, such as race, skin color, weight or age. The test is administered using a computer and should be answered in a maximum of five minutes. The identification of implicit associations is based on points obtained on the congruent and incongruent sets. The congruent set has a shorter mean association time (interval between stimulus and response), whereas the incongruent set has a longer association time. ${ }^{30}$ An association value $\leq 0.15$ on the D score reveals lack of preference; scores 0.16 to 0.35 identify a low association; 0.36 to 0.65 correspond to a moderate association; and values $\geq 0.65$ reveal a strong preference. ${ }^{29}$ The IAT demonstrated high testretest reliability in the study conducted by Greenwald et al. ${ }^{18}$

All studies employed the IAT for the identification of implicit preferences for a young or old target public. Rudman et al.., ${ }^{22}$ Lin et al.., ${ }^{24}$ Azcurra, ${ }^{25}$ Nash et al. ${ }^{26}$ and Merz et al. ${ }^{28}$ used the young/old IAT composed of five or seven sets and performed a total of 180 trials. Ruiz et

Table 1 - Characteristics of seven articles selected for present systematic review

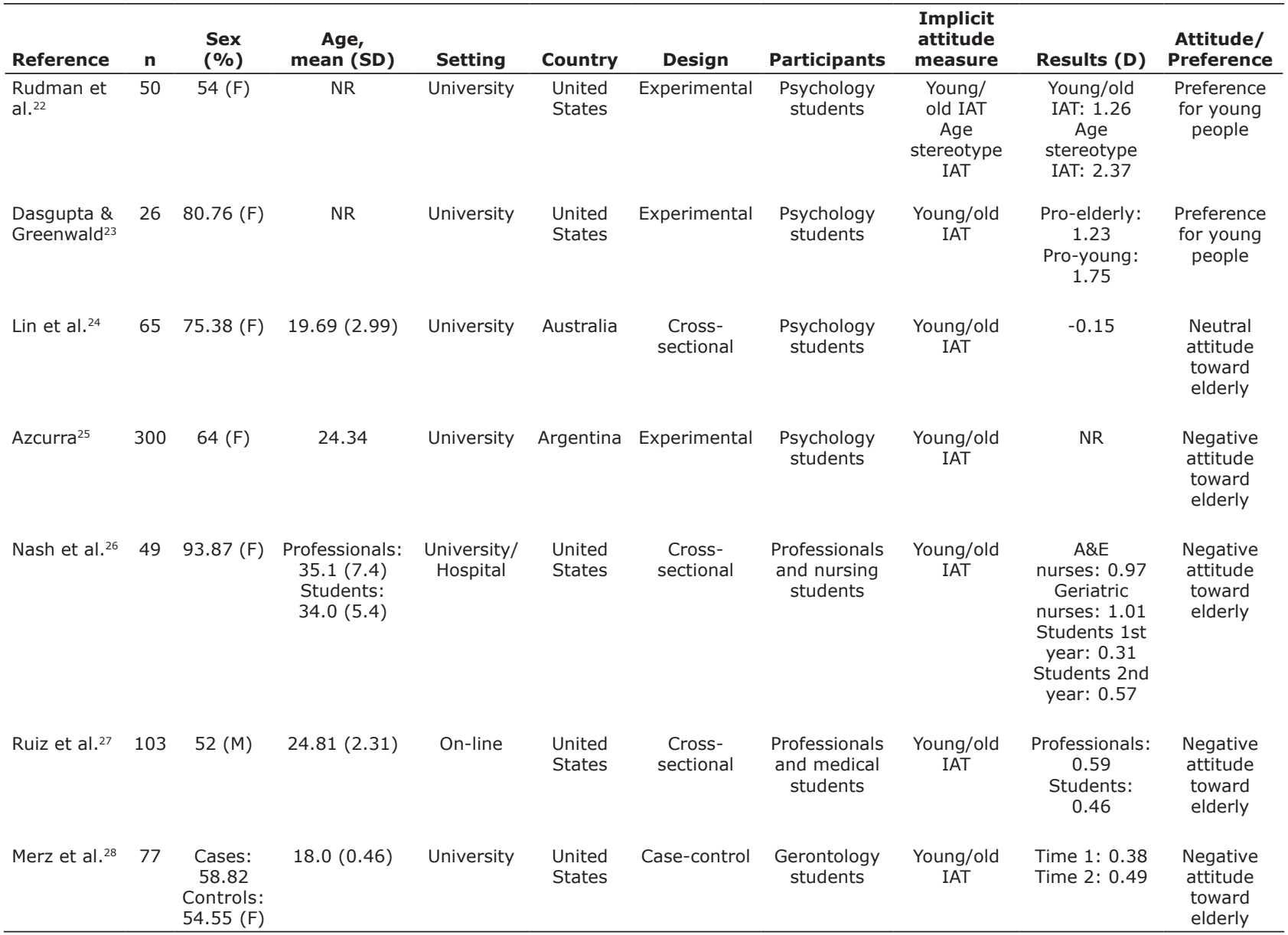

$\mathrm{A} \& \mathrm{E}=$ accident and emergency; $\mathrm{D}=\mathrm{D}$ score according to Sriram \& Greenwald ${ }^{29} ; \mathrm{F}=$ female; IAT = Implicit Association Test; $M=$ male; NR = not reported; $\mathrm{SD}=$ standard deviation. 
al. ${ }^{27}$ used the young/old IAT composed of four sets and performed a total of 60 trials. In addition to the young/ old IAT, Rudman et al. ${ }^{22}$ used an age stereotype IAT composed of five sets and 180 trials. The age stereotype IAT includes a set of tasks (young traits + young people and old traits + young people).

\section{Young/old preferences among health professionals and students}

Among the studies that employed the young/old IAT, the minimum $D$ score was $-0.15^{24}$ and the maximum was $1.26^{22}$. However, the highest $D$ score was found on the age stereotype IAT $(D=2.37)^{22}$.

Regarding preferences and/or implicit attitudes regarding the young/old target public, four studies found negative attitudes toward the elderly ${ }^{25-28}$ and one found a neutral attitude. ${ }^{24}$ Rudman et al. ${ }^{22}$ and Dasgupta \& Greenwald ${ }^{23}$ did not describe positive, negative or neutral attitudes toward the elderly, but demonstrated a preference among the participants for the younger public. Rudman et al. ${ }^{22}$ used two tests: the young/old IAT and age stereotype IAT, which presents negative stereotypes regarding the elderly.

Regarding young/old preferences according to sex, Azcurra ${ }^{25}$ and Ruiz et al. ${ }^{27}$ demonstrated that males had more negative attitudes toward the elderly than females. In contrast, Lin et al. ${ }^{24}$ found no difference in preferences between the sexes. The other studies did not address differences according to sex. ${ }^{22,23,26,28}$

\section{Discussion}

The analysis of the articles selected for the present review reveals negative attitudes toward the elderly on the part of health professionals and students in the health field. Moreover, female professionals and students had more positive attitudes toward the elderly than males.

Few studies have addressed attitudes of professionals and/or students in the health field toward the elderly. However, studies involving other individuals affiliated with universities have demonstrated the same preference. ${ }^{31,32}$ While none of the studies reviewed was performed exclusively with professionals, those involving the participation of health professionals demonstrated more negative attitudes in comparison to students. ${ }^{26,27}$

What could possibly explain this preference is not explicitly presented in these studies. However, some investigations have suggested that negative attitudes toward the elderly public are related to the issues outlined in the introduction, i.e., difficulties dealing with situations of abandonment, death and dependence, communication problems during appointments, and large number of treatments, among others. Lack of contact with elderly patients during one's time at the university ${ }^{33}$ and interactions with elderly individuals in day-to-day living ${ }^{34}$ should also be mentioned.

The experimental studies reviewed $22,23,25$ demonstrated that the participants had negative attitudes toward the elderly during the first evaluation, but such attitudes diminished after the experiment, which involved contact with the elderly public or activities involving images and/or videos. Likewise, a previous study involving young adults found that participation in an educational workshop led to more positive attitudes towards the elderly. ${ }^{35}$ A similar result was found in a study conducted by Schwalbach \& Kiernan ${ }^{36}$ with students who paid weekly visits to a nursing home for a period of five months. Conversely, a study involving 224 students (52 from the nursing program, 127 from medicine and 45 from social service) selected to participate in a geriatrics and gerontology course with diverse activities for one semester concluded that knowledge regarding the elderly was not a factor that could change negative attitudes toward the elderly or awaken interest in working with this public. ${ }^{37}$

According to Schwartz et al., ${ }^{34}$ contact between health students, physicians and nurses with elderly individuals with disease can lead to the persistence or development of negative attitudes. Notwithstanding, the authors also state that the participation of elderly individuals without disease in the same context can favor the non-occurrence of negative attitudes, which is in agreement with findings reported by Wittig \& GrantThompson. ${ }^{38}$

Most of the individuals who participated in the studies here analyzed were female.22-26,28 The predominance of women in the health field has been reported previously. ${ }^{39-43}$ Moreover, women had fewer negative attitudes toward the elderly in the studies reviewed. Investigations conducted by Chopik \& Giasson ${ }^{44}$ with a sample of 704,151 participants, and by Bodner et al. ${ }^{45}$ with 955 participants, also found that men had more negative attitudes toward the elderly than women.

Another important point regards the region in which most studies were conducted. The continents on which most studies were developed have a longer life expectancy compared to South America - where only one study was conducted. ${ }^{25}$ This may explain the lack of this type of study in less developed regions that have a smaller population of elderly individuals. Other studies identified in the databases were conducted in developed regions. ${ }^{31,32,44,45}$ In the United States, more than two million individuals answered the IAT between 2002 and 
2006 , and $80 \%$ of those who completed the young/old IAT demonstrated a preference for young people. ${ }^{46}$

Several measures are used for the identification of implicit attitudes, such as the Affective Priming Task, Sequential Priming Task and IAT, the latter of which is considered one of the most important ${ }^{20}$ and was employed in all studies included in the present review. The IAT is used to identify preferences for different target publics based on race, age, skin color, sex, etc. ${ }^{20}$ and has shown a good reliability index in comparison to other measures with the same purpose. ${ }^{47}$ Moreover, the IAT has shown Cronbach's alpha coefficients between 0.70 and 0.90 , with 0.25 to 0.69 in the test-retest analysis. ${ }^{48}$

The studies included in this review have limitations that should be considered, such as a sample restricted to a single university, ${ }^{27}$ small sample sizes ${ }^{24,27,28}$ and weak statistical analysis due to the small sample size. ${ }^{24}$ As an experimental study, the limitation of the investigation by Aczurra ${ }^{25}$ was the lack of a controlled setting, since the experiment was conducted in the homes of elderly individuals.

\section{Conclusions}

Based on the findings of the present systematic review, both students and professionals in the health field have negative attitudes toward the elderly. Moreover, men have less of a preference for the elderly than women, and health professionals have more negative attitudes than students. Activities involving these professionals/students and elderly individuals may lead to a reduction in negative implicit attitudes and perhaps even awaken interest in working with this population.

Considering the scarcity of investigations with this objective, further studies should be conducted in less developed countries, in an attempt to demonstrate specificities that have not been revealed so far. Also, the present findings underscore the importance of longitudinal studies to identify the cause (contact with the elderly public?) and effect (reduction in negative attitudes?), since most studies have a cross-sectional design.

\section{Acknowledgements}

This study was financed in part by Coordenação de Aperfeiçoamento de Pessoal de Nível Superior (CAPES; finance code 001) through a master's grant awarded to Madson Alan Maximiano-Barreto.

\section{Disclosure}

No conflicts of interest declared concerning the publication of this article.

\section{References}

1. World Health Organization. Noncommunicable diseases prematurely take 16 million lives annually, WHO urges more action. Geneva: WHO; 2015. https://www.who.int/mediacentre/ news/releases/2015/noncommunicable-diseases/en/

2. Fratiglioni L, Launer LJ, Andersen K, Breteler MM, Copeland JR, Dartigues JF, et al. Incidence of dementia and major subtypes in Europe: A collaborative study of population-based cohorts. Neurologic Diseases in the Elderly Research Group. Neurology. 2000;54(11 Suppl 5):S10-5.

3. Dowding $\mathrm{CH}$, Shenton $\mathrm{CL}$, Salek SS. A review of the healthrelated quality of life and economic impact of Parkinson's disease. Drugs Aging. 2006;23:693-721.

4. Ayerbe L, Ayis S, Wolfe CD, Rudd AG. Natural history, predictors and outcomes of depression after stroke: systematic review and meta-analysis. Br J Psychiatry. 2013;202:14-21.

5. Lichtman $\mathrm{JH}$, Froelicher ES, Blumenthal JA, Carney RM, Doering LV, Frasure-Smith N, et al. Depression as a risk factor for poor prognosis among patients with acute coronary syndrome: systematic review and recommendations: a scientific statement from the American Heart Association. Circulation. 2014;129:135069.

6. Bleijenberg N. Dutch nursing students' knowledge and attitudes towards older people -- a longitudinal cohort study. J Nurs Educ Pract. $2012 ; 2: 1-8$

7. Kusumastuti S, van Fenema E, Polman-van Stratum EC, Achterberg W, Lindenberg J, Westendorp RG. When contact is not enough: Affecting first year medical students' image towards older persons. PloS One. 2017;12:e0169977.

8. Seferoğlu M, Yıldız D, Pekel NB, Güneş A, Yıldız A, Tufan F. Attitudes of neurology specialists toward older adults. Aging Clin Exp Res. 2017;29:787-92.

9. Brasil, Ministério da Saúde. Portaria no 2.528 de 19 de outubro de 2006. Aprova a Política Nacional de Saúde da Pessoa Idosa [Internet]. [cited 2019 Feb 10.] http://bvsms.saude.gov.br/bvs/ saudelegis/gm/2006/prt2528_19_10_2006.html

10. American Geriatrics Society. Education in geriatric Medicine. AGS Education Committee and Public Policy Advisory Group (PPAG). J Am Geriatr Soc. 2001;49:223-4.

11. Adelman RD, Greene MG, Ory MG. Communication between older patients and their physicians. Clin Geriatr Med. 2000;16:1-24.

12. Ouchida KM, Lachs MS. Not for doctors only: Ageism in healthcare. Generations. 2015;39:46-57.

13. São José JMS, Amado CAF, Ilinca S, Buttigieg SC, Taghizadeh Larsson A. Ageism in health care: a systematic review of operational definitions and inductive conceptualizations. Gerontologist. 2019;59:e98-108.

14. Grant PT, Henry JM, McNaughton GW. The management of elderly blunt trauma victims in Scotland: evidence of ageism? Injury. 2000;31:519-28.

15. Peake MD, Thompson S, Lowe D, Pearson MG. Ageism in the management of lung cancer. Age Ageing. 2003;32:171-7.

16. Neto F. O Paradigma do Teste de Associação Implícita. Rev E-Psi. 2015;5:1-15.

17. Holroyd J, Sweetman J. The heterogeneity of implicit bias. In: Brownstein M, Saul J, editors. Implicit bias and philosophy. Oxford: Oxford University Press; 2016. p. 80-103. Volume 1: Metaphysics and epistemology.

18. Greenwald AG, Nosek BA, Banaji MR. Understanding and using the implicit association test: I. An improved scoring algorithm. J Pers Soc Psychol. 2003;85:197-216.

19. Greenwald AG, Banaji MR. Implicit social cognition: attitudes, self-esteem, and stereotypes. Psychol Rev. 1995;102:4-27.

20. Lane KA, Banaji MR, Nosek BA, Greenwald AG. Understanding and using the Implicit Association Test: IV. What we know (so far) about the method. In: Wittenbrink B, Schwarz N, editors. Implicit measures of attitudes: Procedures and controversies. New York: Guilford Press; 2007. p. 59-102. 
21. Moher D, Liberati A, Tetzlaff J, Altman DG. Preferred Reporting Items for Systematic Reviews and Meta-Analyses: the PRISMA statement. Ann Intern Med. 2009;151:264-9.

22. Rudman LA, Greenwald AG, Mellott DS, Schwartz JL. Measuring the automatic components of prejudice: flexibility and generality of the Implicit Association Test. Soc Cog. 1999;17:437-65.

23. Dasgupta N, Greenwald AG. On the malleability of automatic attitudes: combating automatic prejudice with images of admired and disliked individuals. J Pers Soc Psychol. 2001;81:800-14.

24. Lin X, Bryant C, Boldero J. Measures for assessing student attitudes toward older people. Educ Gerontol. 2010;37:12-26.

25. Azcurra DS. El trabajo de observación del adulto mayor. Una herramienta pedagógica para modificar actitudes ageístas en estudiantes de psicología. Rev Electron Investig Educ. 2011;13:71-85.

26. Nash $\mathrm{P}$, Stuart-Hamilton I, Mayer $\mathrm{P}$. The continuation of prejudice: addressing negative attitudes in nurse training and continuing professional education. Educ Gerontol. 2014;40:53-60.

27. Ruiz JG, Andrade AD, Anam R, Taldone S, Karanam C, Hogue C, et al. Group-based differences in anti-aging bias among medical students. Gerontol Geriatr Educ. 2015;36:58-78.

28. Merz CC, Stark SL, Morrow-Howell NL, Carpenter BD. When I'm 64: effects of an interdisciplinary gerontology course on first-year undergraduates' perceptions of aging. Gerontol Geriatr Educ. 2018;39:35-45.

29. Sriram N, Greenwald AG. The brief implicit association test. Exp Psychol. 2009;56:283-94.

30. Greenwald AG, McGhee DE, Schwartz JL. Measuring individual differences in implicit cognition: the implicit association test. J Pers Soc Psychol. 1998;74:1464-80.

31. Rothermund K, Wentura D. Figure-ground asymmetries in the Implicit Association Test (IAT). Z Exp Psychol. 2001;48:94-106.

32. Jelenec $P$, Steffens MC. Implicit attitudes toward elderly women and men. Curr Res Soc Psychol. 2002; 7:275-93.

33. Turner RN, Crisp RJ. Imagining intergroup contact reduces implicit prejudice. Br J Soc Psychol. 2010;49:129-42.

34. Schwartz K, Joseph $P$, Simmons L. Contact quality and attitudes toward the elderly. Educ Gerontol. 2001;27:127-37.

35. Glass Jr JC, Knott ES. Effectiveness of a workshop on aging in changing middle $\square$ aged adults' attitudes toward the aged. Educ Gerontol. 1982;8:359-72.

36. Schwalbach E, Kiernan S. Effects of an intergenerational friendly visit program on the attitudes of fourth graders toward elders. Educ Gerontol. 2002;28:175-87.

37. Carmel S, Cwikel J, Galinsky D. Changes in knowledge, attitudes, and work preferences following courses in gerontology among medical, nursing, and social work students. Educ Gerontol. 1992;18:329-42.
38. Wittig MA, Grant-Thompson S. The utility of Allport's conditions of intergroup contact for predicting perceptions of improved racial attitudes and beliefs. J Soc Issues. 1998;54:795-812.

39. Alford $C L$, Miles $T$, Palmer R, Espino D. An introduction to geriatrics for first-year medical students. J Am Geriatr Soc. 2001;49:78287.

40. Noronha APP, Beraldo, FNDM, Oliveira KLD. Instrumentos psicológicos mais conhecidos e utilizados por estudantes e profissionais de psicologia. Psicol Esc Educ. 2003;7:47-56.

41. Conceição MRD, Costa MS, Almeida MID, Souza AMA, Cavalcante MBDPT, Alves MDS. Quality of life for nurses when teaching professionally: a study with the WHOQOL-bref. Esc Anna Nery Rev Enferm. 2012;16:320-5.

42. Brett AL, Branstetter JE, Wagner PD. Nurse educators' perceptions of caring attributes in current and ideal work environments. Nurs Educ Perspect. 2014;35:360-6.

43. Rabelo ALA, Pilati R, Porto JB. O Teste de Associação Implícita para avaliação da preferência profissional em psicologia. Rev Bras Orientac Prof. 2016;17:188-99.

44. Chopik WJ, Giasson HL. Age differences in explicit and implicit age attitudes across the life span. Gerontologist. 2017;57(Suppl 2):S169-77.

45. Bodner E, Bergman YS, Cohen-Fridel S. Different dimensions of ageist attitudes among men and women: a multigenerational perspective. Int Psychogeriatr. 2012;24:895-901.

46. Nosek BA, Smyth FL, Hansen J], Devos T, Lindner NM, Ranganath $K A$, et al. Pervasiveness and correlates of implicit attitudes and stereotypes. Eur Rev Soc Psychol. 2007;18:36-88.

47. LeBel EP, Paunonen SV. Sexy but often unreliable: The impact of unreliability on the replicability of experimental findings with implicit measures. Pers Soc Psychol Bull. 2011;37:570-83.

48. Teige-Mocigemba S, Klauer KC, Sherman JW. A practical guide to implicit association tests and related tasks. In: Gawronsk $\mathrm{B}$, Payne BK, editors. Handbook of implicit social cognition: Measurement, theory, and applications. New York: Guilford Press; 2010. p. 117-39.

\section{Correspondence:}

Madson Alan Maximiano-Barreto

Departamento de Gerontologia (DGERO), Universidade Federal de São Carlos

Rodovia Washington Luís, km 235

13565-905 - São Carlos, SP - Brazil

Tel.: +55 (82) 999208149

E-mail: mmaximianopsi@gmail.com 